\title{
Chlorambucil Plus Rituximab as Front-Line Therapy for Elderly Patients with Comorbidities Affected by Waldenstrom Macroglobulinemia: A Single Center Experience
}

Idanna Innocenti ${ }^{1 \#}$, Andrea Corbingi ${ }^{1 \#}$, Francesco Autore $^{1}$, Federica Sorà ${ }^{1}$, Marco Luigetti ${ }^{2}$, Denise Soldati ${ }^{1}$, Raffaella Pasquale ${ }^{1}$, Simona Sica ${ }^{1}$ and Luca Laurenti* ${ }^{1 *}$

${ }^{1}$ Department of Hematology, Catholic University of the Sacred Heart, Largo A. Gemelli 8, Rome, Italy

'UOC Neurology, Catholic University of Sacred Heart, Largo A. Gemelli 8, Rome, Italy

"Equally contributed to this study

Keywords: Waldenstrom macroglobulinemia; Chlorambucil; Rituximab

\section{Letter}

Waldenstrom Macroglobulinemia (WM) is a rare B-line lymphoproliferative disorder characterized by an infiltration in bone marrow of lymphoplasmacytic lymphocytes producing an IgM monoclonal gammopathy [1]. Considering the indolent nature of the disease, patients who fulfilled diagnostic criteria might not need treatment until progression or onset of symptoms attributable to the tumor [2]. However, BTK inhibitors [3] were not yet available in Italy until 2016. Just recently, ibrutinib [4] has been approved in relapsedrefractory WM patients. Therefore, the traditional standard first line treatment consisted in the association of rituximab, cyclophosphamide and dexamethasone (DRC). It is an effective regimen associated with moderate myelosuppression, especially neutropenia. Overall response rate (ORR) was $83 \%$ ranging from $73 \%$ to $91 \%$, with $7 \%$ complete response (CR) rate and 2-year PFS rate of $67 \%$ and $80 \%$ for DRC responders [5].

As alkylating agents and the anti-CD20 monoclonal antibody rituximab are among the appropriate choices for the primary treatment of symptomatic patients with WM and the comorbidities of our patients, we conducted a retrospective analysis of ChlorambucilRituximab (CHL-RTX) used as front-line treatment in elderly unfit patients ( $\geq 65$ years).

The Essential Criteria addressing patients to treatment, according to NCCN guidelines, were the onset of: 'B' symptoms, cytopenias $\left(\mathrm{Hb}<10 \mathrm{gr} / \mathrm{dL}\right.$ and/or Plts $\left.<100,000 \mathrm{~mm}^{3}\right)$, symptomatic hyper-viscosity, moderate-severe peripheral neuropathy, symptomatic cryoglobulins, cold agglutinins, autoimmune-related events or amyloidosis [6]. Moreover patients had to be older than 65 with an ECOG score $\leq 2$ and comorbidities which ruled out the use of steroids (peptic ulcer, hypertension diabetes). Patients previously treated for WM or with active HIV, B and/or C hepatitis were excluded from this study.

Patients underwent a baseline evaluation before starting each cycle which included blood exams and physical examination. Radiological exams were performed at the beginning of treatment and at the end of the whole cycles or if signs of progression were observed. Primary end-points included overall response rate (ORR) (complete response (CR), very good partial response (VGPR) and partial response (PR)). Time dependent parameters such as progression free survival (PFS), time to retreatment (TTR), and hematological or extra-hematological toxicities were also considered as primary objectives of the study.

Our study was designed as an intention-to-treat study; all patients who underwent to a minimum of $6 \mathrm{CHL}$ and 6 RTX cycles or interrupted them for disease progression or adverse events were admitted into the study. Response assessment was performed 2 months after induction completion according to criteria adopted at the Sixth International Workshop on WM [7].

CHL was administered at $1 \mathrm{mg} / \mathrm{kg}$ for each cycle every 28 days (os) at a fixed daily dose of $10 \mathrm{mg}$ starting from Day $1^{\text {st }}$ and repeated for 8 cycles in order to obtain a better compliance. RTX was added to CHL from the $3^{\text {rd }}$ cycle onwards and was administered on Day $1^{\text {st }}$ of each cycle at a dose of $375 \mathrm{mg} / \mathrm{m}^{2}$ for 6 cycles. This schedule is the same adopted for the chronic lymphocytic leukemia (CLL) in elderly patients, though, using RTX at the steady dose of $375 \mathrm{mg} / \mathrm{m}^{2}$ [8].

Each administration was pre-medicated with acetaminophen 1000 $\mathrm{mg}$, an antihistaminic, protonicpumpinhibitorandmethylprednisolone. Prophylaxis with thrimetoprim-sulphametoxazole was established to reduce risk of Pneumocystis jiroveci infection, twice a day for two consecutive days weekly. Hematological and extra-hematological toxicity was monitored according to the National Institute Common Toxicity criteria (NCCITCT).

In a time span from 2008 to 2015 , ten patients affected by WM who fulfilled the above reported criteria were enrolled in this study and evaluated until December 2016.

Patient characteristics are reported in Table 1. Main reasons to start treatment were the onset of symptoms: anemia (6 out of 10 patients), B symptoms such as weight loss (3 patients), peripheral neuropathy [9] and hyperviscosity syndrome (loss of eyesight) in one patient, respectively. Moreover, one patient needed support with 2 plasma exchanges in order to control IgM paraprotein related symptoms before starting the planned therapy because of severe anemia.

The median number of CHL and RTX cycles administered was 8 (range 1-8) and 6 (range 3-6), respectively. The median total dose of CHL administered during treatment was $512 \mathrm{mg}$ per patient (median dose: $79 \mathrm{mg} /$ cycle) and the median dose of RTX was $3600 \mathrm{mg}$ per patient (median dose: $600 \mathrm{mg} / \mathrm{cycle}$ ). Two patients with low burden of paraprotein were able to avoid the two purging cycles of $\mathrm{CHL}$, undergoing the 6 planned cycles of CHL-RTX. During the period

*Corresponding author: Laurenti L, Department of Hematology, Catholic University of the Sacred Heart, Largo A. Gemelli 8, I-00168 Rome, Italy, Tel: +3906-30156016; Fax: +39-06-3017319; E-mail: luca.laurenti@unicatt.it

Received December 14, 2017; Accepted December 18, 2017; Published December 25, 2017

Citation: Innocenti I, Corbingi A, Autore F, Sorà F, Luigetti M, et al. (2017) Chlorambucil Plus Rituximab as Front-Line Therapy for Elderly Patients with Comorbidities Affected by Waldenstrom Macroglobulinemia: A Single Center Experience. J Blood Lymph 8: 193. doi:10.4172/2165-7831.1000193

Copyright: (c) 2017 Innocenti I, et al. This is an open-access article distributed under the terms of the Creative Commons Attribution License, which permits unrestricted use, distribution, and reproduction in any medium, provided the original author and source are credited. 
Citation: Innocenti I, Corbingi A, Autore F, Sorà F, Luigetti M, et al. (2017) Chlorambucil Plus Rituximab as Front-Line Therapy for Elderly Patients with Comorbidities Affected by Waldenstrom Macroglobulinemia: A Single Center Experience. J Blood Lymph 8: 193. doi:10.4172/21657831.1000193

\begin{tabular}{|c|c|}
\hline $\begin{array}{c}\text { Patients clinical characteristic } \\
\text { At the treatment time } \\
\text { Median age at treatment }\end{array}$ & $\begin{array}{c}\text { Results } \\
\text { (range) }\end{array}$ \\
\hline Male/Female & 69 years (range 65-83) \\
\hline Comorbidities & $7 / 3$ \\
\hline Hypertension & $7 \mathrm{pts}$ \\
\hline Diabetes & $2 \mathrm{pts}$ \\
\hline Peptic ulcera & $2 \mathrm{pts}$ \\
\hline Median bone marrow lymphocytes (range) & $19 \%(11-44 \%)$ \\
\hline IgM level (mg/dL) & $4400(1.250-9.980)$ \\
\hline$\beta 2$ microglobulin (mg/dL) & $3.37(2.5-9.9)$ \\
\hline IPSS (range) & $3(2-4)$ \\
\hline ECOG (range) & $1(0-2)$ \\
\hline Treatment reason & \\
\hline Anemia median value (range) (g/dL) & 6 pts: Hb 9 (7.7-10) \\
\hline B-Symptoms (reason) & $3($ weight loss) \\
\hline Peripheral neuropathy & 1 \\
\hline Hyperviscosity (reason) & 1 (loss of eyesight) \\
\hline
\end{tabular}

Table 1: Patients clinical characteristics.

\begin{tabular}{|c|c|c|}
\hline CHL-RTX administered & Median & Range \\
\hline Number of chlorambucil cycles & 8 & $1-8$ \\
\hline Chlorambucil (mg per cycle) & 79 & $70-100$ \\
\hline Chlorambucil total dose $(\mathrm{mg})$ & 512 & $80-800$ \\
\hline Number of rituximab cycles & 6 & $3-6$ \\
\hline Rituximab $($ mg per cycle) & 600 & $500-700$ \\
\hline Rituximab total dose $(\mathrm{mg})$ & 3600 & $2100-4200$ \\
\hline Response & $\begin{array}{c}\text { Number of } \\
\text { patients }\end{array}$ & \\
\hline ORR & $8 / 10$ & 80 \\
\hline CR & $1 / 10$ & 10 \\
\hline VGPR & $1 / 10$ & 60 \\
\hline PR & $6 / 10$ & Range (months) \\
\hline Time dependent parameter & Median (months) & $(1-93)$ \\
\hline TTR & 31 & Two patients at 24 and 72 \\
\hline
\end{tabular}

ORR: Overall Response Rate; PFS: Progression Free Survival; TTR: Time to Retreatment; Nr: Not reached.

Table 2: Chemo-immunotherapy schedule and results.

under examination, none of the patients experienced a dose reduction of either CHL or RTX because of hematological/extra-hematological toxicities.

On an intent-to-treat-basis, ORR was $80 \%$. Among them one patient showed CR, one achieved a VGPR and six PR. One patient showed stable disease after the end of therapy and was treated again after 24 months. In one patient, therapy was discontinued after one course of CHL and three courses of RTX because of the onset of severe pancytopenia and esophagus necrosis which led the patient to death (Table 2).

Median PFS was reached after 31 months (range: 1-93 months) from the beginning of the treatment. Median TTR was not reached; only two patients who achieved VGPR and SD were retreated after 72 and 24 months, respectively. All patients but one, who died because of progressive disease during treatment, is alive at a median follow-up of 54 months.

CHL-RTX was a very well tolerated regimen: one patient only developed grade 2 neutropenia without infective complications; no patient but one died of progressive disease and was admitted into hospital. Anemia, thrombocytopenia, flare and infusion reactions related to rituximab were recorded in two patients at grade 1 . The median IgM values at baseline and after 2 CHL cycles before the use of RTX, were $4.633 \mathrm{mg} / \mathrm{dL}$ (range $2.905-9980 \mathrm{mg} / \mathrm{dL}$ ) and $3.430 \mathrm{mg} /$ $\mathrm{dL}$ (range 2.220-6.900 $\mathrm{mg} / \mathrm{dL}$ ), respectively. The presented data showed that the association of CHL-RTX is safe and effective.

The standard first line therapy, DRC resulted in $83 \%$ of response and $67 \%$ of PFS at 2 years. However, this regimen resulted in a mild myelosuppression experiencing grade 3-4 neutropenia in almost $10 \%$ of treated patients requiring hospitalization and intravenous antibiotics administration.

When we compared our results with DRC, in which the class of drugs used is the same to CHL-RTX except for steroid, we observed a similar response rate with low side-effects. Our patients because of their comorbidities avoided the use of steroids and experienced CHL as purging therapy before RTX administration. The reduction of burden disease, evaluated with a decrement of IgM Para protein level at the RTX infusion allowed to reduce extra-hematological side-effects as infusion-related reactions and the risk of "flare" especially if used as a single agent therapy [10]. The schedule of CHL allowed a more gentle approach in the elderly with comorbidities, using an overall lower dose of alkylating agent over an extended time in comparison to cyclophosphamide of DRC regimen, used at a rather high dose (1000 $\mathrm{mg} / \mathrm{m}^{2}$ ) administered over 5 days. This lighter approach could also translate in lower hematological toxicities as shown in our results [1].

Because of the moderate toxicity of DRC regimen, CHL-R appeared as a good option as first line treatment in elderly patients with comorbidities for its measured balance between toxicity and response.

\section{References}

1. Morie A, Gertz (2017) Waldenstrom macroglobulinemia: 2017 update on diagnosis, risk stratification and management. American Journal of Hematology 92: 211-214.

2. Dimopoulos MA, Kastritis E, Owen RG, Kyle RA, Landgren O, et al. (2014) Treatment recommendations for patients with Waldenstrom macroglobulinemia (WM) and related disorders: IWWM-7 consensus. Blood 124: 1404-1405.

3. Dimopoulos MA, Anagnostopoulos A, Kyrtsonis MC, Zervas K, Tsatalas C, et al. (2007) Primary treatment of Waldenström macroglobulinemia with dexamethasone, rituximab, and cyclophosphamide. J Clin Oncol 25: 33443349 .

4. Leblond V, Kastritis E, Advani R, Ansell SM, Buske C, et al. (2016) Treatment recommendations from the Eighth International Workshop on Waldenström's Macroglobulinemia. Blood 128: 1321-1328.

5. Laurenti L, Vannata B, Innocenti I, Autore F, Santini F, et al. (2013) Chlorambuci plus Rituximab as Front-Line Therapy in Elderly/Unfit Patients Affected by B-Cell Chronic Lymphocytic Leukemia: Results of a Single-Centre Experience. Mediterranean Journal of Hematology and Infectious Disease 5: e2013027.

6. Johnson SA, Birchall J, Luckie C, Oscier DG, Owen RG (2006) Guidelines on the management of Waldenstrom macroglobulinemia. British Journal of Hematology 132: 686-687.

7. Treon SP (2015) How I treat Waldenström macroglobulinemia. Blood 126: 727728.

8. Treon SP, Tripsas CK, Meid K, Warren D, Varma G, et al. (2015) Ibrutinib in Previously Treated Waldenstrom's Macroglobulinemia. The New England Journal of Medicine 372: 1430-1440.

9. Luigetti M, Frisullo G, Laurenti L, Conte A, Madia F, et al. (2010) Light chain deposition in peripheral nerve as a cause of mononeuritis multiplex in Waldenström's macroglobulinaemia. J Neurol Sci 291: 89-91.

10. Owen RG, Pratt G, Auer RL, Flatley R, Kyriakou C, et al. (2014) Guidelines on the diagnosis and management of Waldenstrom macroglobulinemia. $\mathrm{Br} J$ Haematol 65: 316-333. 